\title{
LOS INICIOS \\ DE LAS TELECOMUNICACIONES \\ EN ESPAÑA: EL TELÉGRAFO *
}

ÁNGEL CALVO CALVO

Universidad de Barcelona

«Un palo del telégrafo, plantado allí como pendón de conquista, con sus jicaras blancas y sus alambres paralelos, a derecha e izquierda, representaba... el ancho mundo desconocido, misterioso, temible, eternamente ignorado.»

(L. Alas «Clarín», Adiós «Cordera»)

\section{RESUMEN}

La importancia que ha tenido el telégrafo en el desarrollo del comercio, sea como soporte técnico del ferrocarril o, directamente, como medio de acelerar la transmisión de información y de reducir los costes operativos en las empresas, ha venido atrayendo la atención de numerosos especialistas extranjeros. Este artículo sitúa el caso español, escasamente estudiado todavía, en perspectiva europea, destacando los condicionamientos económicos e institucionales que pesaron sobre el primer sistema telegráfico. A diferencia de lo sucedido con el ferrocarril y el teléfono, el telégrafo fue construido y explotado por cuenta del Estado. Falta de medios, atraso económico, subordinación a intereses propiamente administrativos y desvinculación de los objetivos de mercado hicieron que España fuera a la zaga de otros países europeos en el desarrollo del servicio telegráfico.

N. de E.: Fecha de recepción del artículo en la Revista de Historia Económica: septiembre de 2000.

Fecha de aprobación por el Consejo de Redacción: noviembre de 2001.

" Agradezco las ayudas financieras recibidas de la Secretaría de Estado de Universidades, Investigación y Desarrollo (proyecto PB98-0875) y del programa SGR2000-00009. Hago extensiva mi gratitud a todos los que han contribuido desinteresadamente a mejorar el texto con sus observaciones y, de forma especial, a Francesca Antolín, Carles Sudrià y Alfonso Herranz, compañeros del Departamento de Historia e Instituciones Económicas de la Universidad de Barcelona, así como a un referee anónimo. 


\section{ABSTRACT}

The telegraph has been of great importance in the development of commerce, both as a technical support of railways and as a means of accelerating the transmission of information and of cutting transaction costs in the firms. This article places the Spanish case, seldom considered by the literature, in a European context. It outlines the economic and institutional factors which affected the first Spanish telegraphic system. Unlike what happened with the railways and the telephone, the telegraph was state constructed and owned. For different reasons, Spain lagged behind other European countries in the evolution of the telegraphic service.

En el siglo XIX, una impresionante oleada de cambio tecnológico transformó radicalmente los sistemas tradicionales de telecomunicación por medio de señales, acelerando la transmisión de información '. Los nuevos sistemas, telegrafía y telefonía eléctricas, pertenecían al grupo de macroinvenciones que alcanzaron su madurez en la segunda revolución tecnológica ${ }^{2}$. Técnicamente complementarios de la prensa y del ferrocarril, que les habían precedido, impulsaron la creación de grandes empresas y se convirtieron en un componente esencial de la civilización de masas. Su impacto sociocultural también fue importante ${ }^{3}$, como lo demuestra el encabezamiento de estas líneas. Hoy en día, en plena era de la telefonía móvil, del cable y de los satélites, el telégrafo pudiera parecer ya pura arqueología. Pero si se considera la efectividad de la comunicación, ocupa los eslabones intermedios en la cadena tecnológica que engloba desde el mensajero hasta la radio y la televisión.

El telégrafo ha atraído la atención de cualificados analistas internacionales por su contribución al surgimiento de la sociedad industrial avanzada ${ }^{4}$. La bibliografía ha subrayado su impacto en el desarrollo económico, debido a la aparición de mercados crecientemente articulados que reducen los costes operativos, aumentan la circulación de mercancías y alientan la especialización ${ }^{5}$. Pese a su importancia y a diferencia del interés des-

' Hobsbawm (1977), p. 88; Kenwood y Lougheed (1982), p. 147, y Standage (1999). La versión revisionista ha sido mantenida recientemente por Kaukiainen (2001), pp. 1-28.

2 Mokyr (1990), Headrick (1990) y Malone (2000), pp. 123-134.

'Field (1987); Martwell (1979), p. 389, y Caron (1997), pp. 101 y 114.

+ Estabrooks (1995).

'Lamoreaux y Sokoloff (1999). Entre las aportaciones recientes, destacan: Du Boff (1983), pp. 253-277; Carlsson (inédito); Casson (1994); Field (1999), p. 496, y Nonnenmacher (1997). Dos direcciones de investigación prometedoras en la actualidad son las que se refieren a la contribución de los servicios, por un lado, y de las infraestructuras, por 
pertado en la historiografía de otros países ${ }^{6}$, el telégrafo no ha suscitado excesivo entusiasmo en el nuestro. Algunos pocos estudios llevados a cabo en los últimos años son una incipiente respuesta a la brecha abierta por N. Sánchez-Albornoz con un trabajo sobre el impacto de las comunicaciones en la historia económica contemporánea a partir del correo ${ }^{7}$. Es, pues, urgente incorporar el telégrafo a los estudios de Historia Económica de España. En respuesta a la premura, este trabajo se limita a describir en sus características esenciales la creación del sistema telegráfico español, con ánimo de desbrozar el camino a futuras investigaciones analíticas y comparativas.

\section{EL TELÉGRAFO ELÉCTRICO Y SU DIFUSIÓN POR EUROPA}

Desde tiempos remotos, el hombre ha intentado comunicarse a distancia con sus semejantes usando diferentes tipos de señales. Fuera de la comunicación por señales, el correo y la prensa escrita han desempeñado un papel importante. Un avance notable en la transmisión de información se dio con el telégrafo óptico, inventado por $\mathrm{Cl}$. Chappe en 1792 con fines militares ${ }^{8}$. Esencialmente, aportaba un aumento en la velocidad de transmisión y un enlace permanente, junto a un cuerpo técnico especializado y un código ${ }^{9}$. Adoptado primero en Francia, país que disponía del sistema más extenso y perfecto, se difundió por Europa, casi siempre a partir de modificaciones nacionales del sistema Chappe. Pero su elevada sensibilidad hacia las perturbaciones atmosféricas y su relativa lentitud le hacían poco apto para una explotación comercial sin discontinuidades ${ }^{10}$.

otro, al crecimiento. La primera cuenta entre sus analistas a Gemmell y Bardley (1990), pp. 299-321, Krantz (2000), pp. 5-29, y el monográfico dirigido por A. Giuntini en Memoria e Ricerca, núm. 5, 2000; para la segunda, cultivada en nuestro pais por autores como A. Herranz, véase Röller y Waverman (2001), pp. 909-923.

'Entre otros, Du Boff (1983), pp. 253-277; Israel y Neir (1991); Barry (1992), p. 199, y Davids (1995), pp. 194-205.

Otero Carvajal (1993), en Bahamonde Magro (1993), pp. 121-127; Bahamonde Magro; Martínez Lorente y Otero Carvajal (1998); Calvo (1993), pp. 189-205; Capel y Tatjer (1994a y 1994b) El estudio pionero es el de Sánchez-Albornoz (1975), pp. 85-97.

Se componía de una línea de torres en cuya cima se acoplaba un mástil con brazos de madera susceptibles de adquirir posiciones diferentes para emitir el mensaje: Field (1994), pp. 315-347; Carré (1992), p. 282.

${ }^{9}$ Flichy (1993), p. 322.

10 Francia construyó $5.000 \mathrm{~km}$ de líneas: Vail (1845), p. 104. El dominio napoleónico 
Sin duda, el artífice de la revolución en las telecomunicaciones fue el telégrafo eléctrico. Se necesitó una compleja y no lineal combinación de observaciones, investigaciones y experimentos ${ }^{11}$ antes que los logros decisivos de W. F. Cooke y Ch. Wheatstone (1837) y de S. F. B. Morse hicieran posible el desarrollo de la telegrafía comercial ${ }^{12}$. La base tecnológica de la telegrafía eléctrica residió por mucho tiempo en el sistema Morse de 1837, que tenía la virtud de reunir un sencillo aparato impresor y un código. Sucesivos avances permitieron aumentar el sincronismo y el automatismo, en respuesta a las exigencias de mayor fidelidad y velocidad en la transmisión del mensaje ${ }^{13}$

De forma directa, el telégrafo eléctrico respondía a la necesidad de transmitir rápidamente la información para facilitar el buen funcionamiento de una nueva red técnica, como era el ferrocarril ${ }^{14}$. También fue recibido como un poderoso instrumento para reforzar la seguridad de los estados nacionales, agilizar la circulación de noticias y reducir los costes operativos. Tales cualidades explican sustancialmente su enorme impacto ${ }^{15}$.

A partir de 1845, el telégrafo eléctrico se difundió por el continente europeo ${ }^{16}$ con marcadas diferencias de ritmo entre países, diferencias a las que la importancia de los sistemas previos, la extensión territorial y el desarrollo económico no fueron ajenos. Hacia 1850, grandes conjuntos territoriales como Gran Bretaña, el Imperio alemán, Francia, el Imperio austro-húngaro, pero también pequeños países avanzados como Suiza, contaban con sistemas muy extensos ${ }^{17}$.

sobre el continente retrasó la construcción de telégrafos ópticos, que en Gran Bretaña existían desde finales del siglo xviI: Holcombe (1911), p. 5. Suecia adoptó un modelo modificado en el país, que resultó ser el preferido en Inglaterra.

1 Dictionnaire (1832). Eslabones claves fueron los avances en las fuentes de alimentación (pilas), en las corrientes y en los aparatos (amperímetros, galvanómetros y aparatos de agujas): Hunt (1991), pp. 1-2; Gavarret (1861).

${ }_{12}$ Coe (1993).

${ }^{13}$ Engineering, 13 de junio de 1890, p. 701. Las mejoras introducidas en el sistema automático de $\mathrm{Ch}$. Wheatstone y en las líneas permitieron multiplicar por seis la velocidad de transmisión entre 1870 y 1887 .

${ }^{14} \mathrm{La}$ principal fuente de ingresos de la Electric Telegraph Co., titular desde 1846 de la patente de Cooke y Wheatstone, fueron los contratos con las compañias ferroviarias: Williams (1881), p. 9. (1913)

${ }^{15}$ Farr (1876), p. 484. Acerca de la explotación comercial del telégrafo, véase Lee

${ }^{16}$ Las primeras líneas telegráficas de Bélgica e Italia, por ejemplo, datan de 1846: O'Meara (1913); las primeras de Austria se remontan a 1847; las de Noruega, a 1851: Foreman-Peck y Müller (eds.) (1988), pp. 53 y 222.

17 Bureau International des Administrations Télégraphiques (BIAT) (Berna), y para Gran Bretaña, Williams (1881), p. 9 
Las diferencias en las tasas de equipamiento y de utilización, expresadas por la densidad de las líneas y por el número de telegramas por habitante, también fueron notables. Las cifras del Cuadro 1 muestran que en 1873

\section{CUADRO 1}

Implantación del telégrafo en Europa (1873-1892)

\begin{tabular}{|c|c|c|c|c|c|}
\hline & $\begin{array}{l}\text { 1. Densidad } \\
\left(\mathrm{km} / \mathrm{km}^{2}\right)\end{array}$ & $\begin{array}{l}\text { 2. Tlgr/hab. } \\
\text { (numero) }\end{array}$ & $\begin{array}{l}\text { 3. Densidad } \\
\left(\mathrm{km} / \mathrm{km}^{2}\right)\end{array}$ & $\begin{array}{l}\text { 4. } \mathrm{Ca} / \mathrm{Tlgr} \text {. } \\
\text { (número) }\end{array}$ & $\begin{array}{l}\text { 5. Tlgr/hab. } \\
\text { (número) }\end{array}$ \\
\hline & 1873 & & 1879 & & 1892 \\
\hline 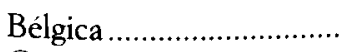 & 0,68 & 0,471 & 0,812 & 46 & 0,436 \\
\hline Gran Bretaña *............... & 0,54 & 0,704 & 0,563 & 46 & 1,632 \\
\hline 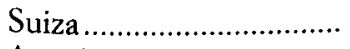 & 0,34 & 0,753 & 0,390 & 30 & 0,655 \\
\hline 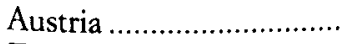 & 0,26 & 0,173 & 0,303 & 57 & \\
\hline 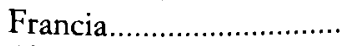 & 0,25 & 0,387 & 0,341 & 34 & 0,818 \\
\hline Alemania............................. & 0,23 & 0,280 & 0,441 & 49 & 0,437 \\
\hline 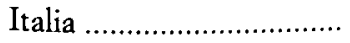 & 0,21 & 0,173 & 0,284 & 32 & 0,224 \\
\hline 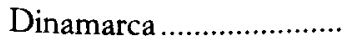 & 0,17 & 0,282 & 0,217 & 42 & 0,287 \\
\hline 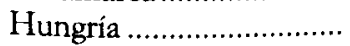 & 0,14 & 0,146 & 0,164 & 34 & \\
\hline 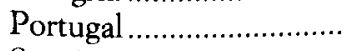 & 0,07 & & & & \\
\hline 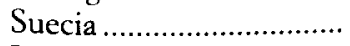 & 0,05 & 0,166 & 0,065 & 44 & 0,240 \\
\hline 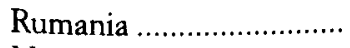 & 0,05 & 0,105 & 0,052 & 19 & \\
\hline 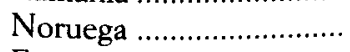 & 0,03 & 0,307 & 0,049 & 17 & 0,531 \\
\hline 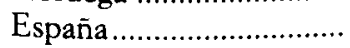 & $0,02 * *$ & 0,089 & 0,078 & 57 & \\
\hline 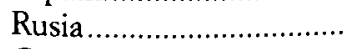 & 0,005 & 0,060 & 0,303 & 21 & \\
\hline 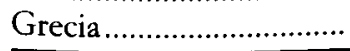 & & 0,196 & 0,090 & & \\
\hline
\end{tabular}

* En 1979 y 1892, Gran Bretaña comprende también Irlanda.

** España: 1875.

NOTA: La primera y tercera columnas expresan la relación entre longitud de los hilos telegráficos y la superficie del país en 1873 y 1879 ; la segunda y la quinta, el número de telegramas por habitante en 1879 y 1892; la cuarta, la relación entre numero de cartas $y$ el de telegramas.

FUENTE: Elaboración a partir de BIAT (1875); Toussaint (1881), p. 473, y The Electrician (1894), 12 de enero, p. 276; para España: Anuario(s) Estadístico(s) de España.

Gran Bretaña y Bélgica eran casos modélicos, ya que presentaban las líneas más densas. Otros datos dan a ambos países la eficiencia más elevada de Europa, medida en número de telegramas por persona empleada. Se trataba de países significativos respectivamente por su liderazgo mundial y por sus ventajas de situación como nudo clave entre Inglaterra y Ale- 
mania ${ }^{18}$. El paso del tiempo pareció jugar en favor de las dos grandes potencias desarrolladas. Ocho años antes de finalizar el siglo, Inglaterra y Francia ${ }^{19}$ se situaban a la cabeza en la utilización del telégrafo, según el número de telegramas por habitante. Alemania, ya unificada y con recursos, estaba superando su desfase inicial, pero los países nórdicos ${ }^{20}$, en que el telégrafo había crecido con extremada rapidez, perdían posiciones. Muy posiblemente, pues, la etapa de inelasticidades en la demanda se estaba superando en la mayoría de los países europeos ${ }^{21}$.

Las diferencias entre países atañían también a la modalidad de explotación del servicio telegráfico: pública en Europa continental por razones administrativas, militares y de orden público; privada en Gran Bretaña, donde las necesidades militares o de seguridad frente al exterior pesaban menos ${ }^{22}$. Si tenemos en cuenta experiencias extraeuropeas, el modelo británico de gestión privada se diferenció del estadounidense por el régimen de explotación. Poco tenía que ver el monopolio ejercido en Estados Unidos por una empresa gigantesca, la Western Electric, con la colaboración entre empresas de diverso tamaño, propia de Gran Bretaña ${ }^{23}$. A su vez, el modelo estadounidense y el europeo se diferenciaron por la eficacia en la gestión: bajos rendimientos, altos costes unitarios e ineficacia de las subvenciones se unieron por lo general en el caso de Europa ${ }^{24}$.

Diferencias en los regímenes de explotación tuvieron como corolario discrepancias en la tecnología ${ }^{25}$, que chocaban con las externalidades de red, sobre todo teniendo en cuenta que el telégrafo se había configurado

${ }^{18}$ Foreman-Peck (1989), p. 387. Con el tiempo, los cables alemanes pondrían en entredicho esa ventaja belga: Journal Télégraphique, 1896, p. 159.

19 La red francesa de telegrafía eléctrica, resultado de la ejecución sucesiva de diversos planes de conjunto, se vio entorpecida por la imposición del servicio de distribución de telegramas a los ayuntamientos.

${ }^{20}$ Para Suecia, véase Carlsson, p. 9 (inédito, cortesía de Marc Prat).

${ }^{21}$ Ya en 1873 , tan sólo el 0,4 por 100 de los telegramas se debían a comunicaciones de los gobiernos. Más tarde, en 1896, en Austria, Bélgica y Países Bajos entre el 50 y el 55 por 100 de los telegramas se debían a operaciones de comercio, bolsa e industria: BIAT (1873), p. 6; Journal Télégraphique, 1896.

${ }^{22}$ Los telégrafos británicos quedaron en manos de cuatro compañías grandes y diversas de pequeño tamaño, antes de ser nacionalizados en 1870: Perry (1997), p. 417; Foreman-Peck y Müller (eds.) (1988).

${ }^{23}$ Adams y Butler (1999); Perry (1997), p. 417.

${ }^{24}$ Foreman-Peck (1989), p. 383. En Estados Unidos, la telegrafía adquirió un marcado carácter urbano tras la guerra civil: Preece (1894), p. 354; The Electrician, 9 de noviembre de 1894, p. 57; Israel (1992).

${ }^{25}$ En Europa continental predominó el sistema Morse, salvo en Francia, que adoptó uno propio (Baudot); fuera del continente, también Gran Bretaña fue una excepción. A 
como un sistema mundial ${ }^{26}$. De ahí la urgencia de uniformizar los sistemas por encima del control monopolístico que los correspondientes gobiernos ejercían sobre sus propios sistemas. El resultado fue la firma de acuerdos entre países y la creación de una organización especializada estable, encargada de regular diversos aspectos del tráfico telegráfico ${ }^{27}$. Así, en las telecomunicaciones se introducían elementos de cooperación, en lugar de una competencia frontal.

\section{LOS SISTEMAS NACIONALES: EL TELÉGRAFO EN ESPAÑA}

España hizo aportaciones de interés a la telegrafía en su etapa inicial, gracias a figuras como el canario Betancourt y el catalán Salvà i Campillo ${ }^{28}$. Nada de ello tuvo consecuencias directas para el desarrollo ulterior del telégrafo en el país. Sí gozó de cierta aceptación la telegrafía óptica, al servicio de fines militares desde comienzos del siglo $\mathrm{XIX}^{29}$ y con miras civiles más adelante ${ }^{30}$. A diferencia de lo sucedido en la mayoría de países europeos, España contó con una auténtica red con derivaciones por el conjunto del territorio ${ }^{31}$. Concebida en parte simultáneamente al trazado de la red de carreteras, su dimensión nacional al servicio del orden público y su desarrollo radial marcarían con su impronta la que ya era una alternativa viable en el terreno de las telecomunicaciones.

Superada la turbulenta situación de enfrentamiento civil, el Gobierno decidió impulsar un sistema nacional de telegrafía eléctrica. La construcción y mantenimiento de los telégrafos ópticos había contribuido a establecer

lo largo del tiempo, incluso en la misma central coexistieron diversas variantes de telégrafo eléctrico, según la finalidad que se persiguiera: Gérard (1889), pp. 444-446.

${ }^{26}$ Nier y Butrica (1998), pp. 211-226.

27 Se ocupaba, entre otros, de tarifas, código o tecnología: The Electrician, 15 de enero de 1897 , p. 373.

${ }^{28}$ Betancourt colaboró con los mejores técnicos franceses (Bréguet): Chappe (1824), pp. 184-185; Iglèsies (1965) y Ribot (1886), p. 479

${ }^{29}$ Memorial del Arma de Ingenienos, junio de 1996, pp. 131 y 147 (cortesía del capitán de Ingenieros Santos Alonso).

${ }^{30}$ Un plan de telegrafía óptica para el conjunto del territorio no llegó hasta 1837 y su realización efectiva hubo de esperar unos años. En 1844, el gobierno adjudicó por concurso la construcción a J. M. Mathé, que competía con otros cuatro proyectos: Suárez Saavedra (1880), p. 141.

${ }^{31}$ Flichy (1993), p. 325; Wilson (1976), pp. 183-184 (cortesía de F. Antolín). En Andalucía, los santsimonianos alentaron una red de telegrafía óptica que reutilizase las atalayas árabes: Maluquer de Motes (1977), p. 126. En Cataluña, Mathé construyó una red militar, independiente de la estatal: González y Molada (1875). 
una infraestructura que sería utilizada en el nuevo sistema. Pero se necesitaban conocimientos específicos y personal adecuado. Aquéllos fueron a buscarse en las experiencias europeas; éste se consiguió inicialmente instruyendo a un grupo de torreros de telegrafía óptica ${ }^{32}$.

El paso decisivo se dio en 1855 con un proyecto de telegrafía eléctrica para todo el territorio peninsular que pretendía garantizar el servicio incluso a las poblaciones con menos recursos ${ }^{33}$. Decidido a recuperar el atraso, el Gobierno buscaba una realización rápida y sin trabas presupuestarias, distribuyendo en cinco ejercicios los quince millones de reales necesarios. El Gobierno pretendía concluir las líneas telegráficas en un año. Pero una serie de dificultades impidieron llevarlo a cabo antes de 1858, con el consiguiente retraso en el inicio del servicio ${ }^{34}$.

La segunda fase de construcción de líneas telegráficas, iniciada en 1859 y dotada de un presupuesto de 17 millones de reales, pretendía desarrollar la red, paliando las deficiencias del primer proyecto. En sus aspectos esenciales, buscaba dar prioridad a las zonas que, como las Baleares, habían quedado excluidas del primer sistema; construir líneas transversales de enlace con las principales y cerrar polígonos y crear nuevas estaciones telegráficas en poblaciones importantes.

Ambas fases explican que el gran empuje en el desarrollo de la red se diera entre 1855 y 1865 (Cuadro 2). A continuación, la construcción de nuevas líneas sufrió un claro estancamiento, debido, sin duda, a la depresión económica que aquejó al país ${ }^{35}$. La construcción se reanudó en 1873 , durante el sexenio revolucionario. Con un presupuesto total de 3,6 millones de reales, financiado con un crédito extraordinario, el Gobierno impulsó una ampliación y reforma de la red que reforzase tanto las conexiones internacionales con Francia y Portugal como las líneas radiales y transversales ${ }^{36}$. Más adelante, aún hubo saltos cuantitativos importantes en los quinquenios que acaban en 1890 y 1910, como se desprende del Cuadro 2.

${ }^{32}$ El Gobierno encomendó una misión de estudio a J. M. Mathé, director de telégrafos y responsable de instruir a los torreros: RO de 6 de octubre de 1852, Gaceta de Madrid, 7 de octubre de 1852 .

${ }^{33}$ DSC, 15 de enero de 1855, pp. 1387-1392.

${ }^{34}$ En el primer trimestre de 1858, tan sólo funcionaba la mitad de las estaciones. La escase $z$ de arbolado, transportes y operarios parecen razones poco convincentes para explicar el retraso: DSC, 22 de abril de 1858 , p. 1311.

${ }^{35}$ Tortella (1994), p. 109. Las cifras son contradictorias: Garrido (1865), p. 449, no coincide, por ejemplo, con $A E E$.

${ }^{36}$ DSC, 1 de febrero de 1873 y 5 de marzo de 1873; Diario de Sesiones de la Asamblea Nacional (DSAN), 5 y 7 de marzo de 1873. 


\section{CUADRO 2}

Evolución de la telegrafía en España

\begin{tabular}{|c|c|c|c|}
\hline Año & Lineas $(\mathrm{km})$. & Oficinas & Telegramas \\
\hline $1855 \ldots \ldots \ldots \ldots \ldots \ldots$ & 713 & 14 & 72.930 \\
\hline $1860 \ldots \ldots \ldots \ldots \ldots \ldots$ & 7.215 & 122 & 259.909 \\
\hline $1865 \ldots \ldots \ldots \ldots \ldots$ & 11.253 & 215 & 724.068 \\
\hline $1870 \ldots \ldots \ldots \ldots \ldots \ldots$ & 11.601 & 199 & 775.862 \\
\hline $1875 \ldots \ldots \ldots \ldots \ldots$ & 12.259 & 262 & 1.590 .821 \\
\hline $1880 \ldots \ldots$ & 16.124 & 365 & 1.714 .012 \\
\hline $1885 \ldots \ldots$ & 17.839 & 914 & 3.322 .687 \\
\hline 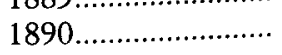 & 24.766 & 1.064 & 3.507 .579 \\
\hline $1895 \ldots$ & 28.797 & 1.428 & 3.630 .900 \\
\hline $1900 \ldots \ldots$ & 32.494 & 1.491 & 3.356 .000 \\
\hline 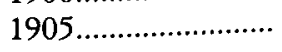 & 33.077 & 1.664 & 3.623 .100 \\
\hline $1910 \ldots \ldots \ldots \ldots \ldots$ & 42.934 & 1.902 & 4.660 .900 \\
\hline $1915 \ldots \ldots \ldots \ldots$ & 47.131 & 2.299 & 6.016 .800 \\
\hline 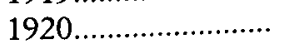 & 51.934 & 2.808 & 11.594 .200 \\
\hline $1925 \ldots \ldots \ldots \ldots \ldots \ldots$ & 50.808 & 2.944 & 10.058 .200 \\
\hline 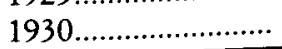 & 53.135 & 2.902 & 7.924 .700 \\
\hline
\end{tabular}

NOTA: La cifra de telegramas de 1865 es una estimación; la señalada como de 1895 es de 1896.

FUENTE: AEE; AOCT (1880-1881); Joumal Telégraphique; Suárez Saavedra (1880), p. 550; Gómez Mendoza, en Carreras (1989), p. 316; Otero Carvajal (1993), p. 122, y Bahamonde Magro (1993), pp. 175 ss.

En el contexto europeo, España aparece como un ejemplo de inicio tardío y de despegue lento, como hemos visto en el Cuadro 1. A finales del siglo XIX, cuando la telegrafía había avanzado considerablemente en muchos países de Europa, España tenía las tarifas más elevadas del continente, junto con Rusia, y la peor dotación de oficinas. No es de extrañar, pues, la escasa inclinación del público por este medio de comunicación, hecho que dio como resultado bajas tasas de utilización, medidas en telegramas por habitante. La distancia abismal entre el número de cartas que circulaban por el interior del país y la cantidad de telegramas indica que el telégrafo quedó confinado a la esfera administrativa y al mundo de los negocios, con enorme ventaja para este segundo, si bien a un nivel comparativamente bajo ${ }^{37}$.

${ }^{37}$ España tenía peores tasas de equipamiento (oficinas por kilómetro cuadrado) y de 
La configuración territorial y política de España exigió la construcción de un sistema público de cables submarinos como prolongación de la red terrestre, para enlazar con los territorios insulares (Baleares y Canarias). La empresa predominante como suministradora de material de línea tanto en los trayectos entre la Península y las islas como en el norte de África fue Pirelli ${ }^{38}$. En el sistema mundial de cables submarinos, durante mucho tiempo liderado por Gran Bretaña, España tuvo siempre una posición subordinada. Por un lado, desperdició su posición estratégica privilegiada, que sí atrajo el interés de las grandes compañías extranjeras como territorio donde amarrar cables vitales para la red internacional. Miopía y cortedad de medios económicos se unieron para otorgar las concesiones a las compañías británicas, que no dudaron en imponer tarifas elevadas en las conexiones internacionales. Por otro lado, los gobiernos españoles reaccionaron tarde en la carrera para establecer una conexión adecuada con los enclaves africanos, mientras problemas presupuestarios lastraron la construcción de las líneas proyectadas en las colonias americanas ${ }^{39}$. La dependencia respecto a las grandes potencias en materia de cables transoceánicos lesionó los intereses coloniales de España al desatarse la insurrección cubana en los años finales del siglo Xx. Cuando el ministro de Ultramar se empeñó en tender un cable de 5.100 millas para unir directamente la Península con las Antillas ya era demasiado tarde ${ }^{40}$.

\section{EL ESTADO Y LA TELEGRAFÍA ELÉCTRICA EN ESPAÑA}

Sectores representativos del tejido social del país reclamaron a los poderes públicos actuaciones concretas, sin coincidir necesariamente en la modalidad de explotación. Valgan como ejemplo las gestiones de la Sociedad Económica de Amigos del País en favor de una línea entre Barcelona y

utilización (telegramas por habitante) que Portugal, por ejemplo, mientras que las tarifas eran más caras. En 1877-78, el número de cartas del interior de la Península se elevó a 61,7 millones, frente a 2.409 telegramas: Anuario Oficial de Correos de España (AOCT), Madrid, 1878, pp. 116-117. A finales del siglo XIX, el número de telegramas oficiales apenas llegaba a la quinta parte de los privados.

${ }^{38}$ Del Grande (1944), p. 3, y Jona (1896), pp. 38-39 (cortesía de Viviana Rocco, Archivio Storico Pirelli ); Bezza (1987), p. 59; Journal Télégrapbique (1899), p. 157.

${ }^{39}$ Arcarons (1993), pp. 151-164. En Puerto Rico se proyectaron diversas líneas: AHN, Madrid, Ultramar.

40 Depelley (1900), p. 200; DSC, 21 de mayo de 1897, 24 de abril y 13 de mayo de 1898 . 
la frontera francesa a cargo del Gobierno ${ }^{41}$. Por su parte, varios diputados catalanes solicitaron la construcción de la línea de Barcelona, aunque fuese por particulares. De la misma manera, diversas empresas privadas intentaron hacerse con las líneas más importantes ${ }^{42}$. Estas iniciativas sirvieron para presionar al Gobierno, que se inclinó por el sistema continental de explotación, es decir, el público, no sin que se manifestaran ciertas resistencias dentro incluso de la propia Dirección General de Telégrafos ${ }^{43}$

Fueron los progresistas los que impulsaron un sistema completo de telegrafía eléctrica de carácter público, conscientes de que ese invento de las ciencias «por sí solo bastaría para marcar el siglo» ${ }^{44}$. El monopolio telegráfico público, establecido por la Ley de 22 de abril de $1855^{45}$, se mantuvo por encima del color político de los sucesivos gobiernos y ha sido una característica permanente del caso español.

La opción por el carácter público del servicio contradice la propensión de los liberales españoles a reducir el tamaño del sector público, recurriendo a concesiones y arrendamientos. En materia de telégrafos, se situaron próximos a la política seguida con las infraestructuras de carreteras y alejados de la actuación más discreta en las obras ferroviarias e hidráulicas ${ }^{46}$.

El carácter irrenunciablemente público de la red quedaba ya reflejado en el proyecto de ley de 1855 , que recogía el sentir de círculos cualificados de la sociedad civil, como la Academia de Ciencias de Madrid ${ }^{47}$. El Gobierno progresista rechazó de plano las ofertas privadas por considerarlas «gravosas al Estado y nocivas a los más respetables intereses de la sociedad». El coste no era tan crecido como para que el Estado no pudiera asumirlo sin renunciar a la titularidad. Como representante de los intereses generales, el Estado era el único que podía garantizar la universalidad y seguridad del servicio. Por el contrario, el móvil lícito del lucro privado repercutiría negativamente en las tarifas o en la forma del servicio, privando a los usuarios de los beneficios y obligando al Estado a intervenir. Además, el afán de la empresa privada por apropiarse de privilegios exclusivos sería

4 Boletin de la Sociedad Barcelonesa de Amigos del País, 1854, pp. 28 y 30.

42 DSC, 15 de enero y 21 de abril de 1855.

${ }^{43}$ Testimonio del diputado E. Figueras, del ala izquierda del progresismo: DSC, 21 de abril de 1855 , p. 4008 .

${ }^{44}$ DSC, 1 de febrero de 1873. Se hacía un encendido canto a esos «débiles alambres, mágicos conductores de la palabra»: DSC, 23 de marzo de 1855, p. 3209.

${ }^{45}$ Gaceta de Madrid, 24 de abril de 1855.

46 Comín (1996); Comín y otros (1998), p. 319; Gómez Mendoza, en Comín y Martín Aceña (dir.) (1991), pp. 177-204. Miñana)

Informe de la Academia de Ciencias de Madrid (1856) (cortesía de Jesús Sánchez 
una rémora para incorporar las innovaciones tecnológicas y una barrera para futuros interesados en el negocio. En definitiva, los progresistas sostenían que el servicio telegráfico en manos privadas conducía al monopolio, mientras que el Estado garantizaba la igualdad ${ }^{48}$. Así pues, la titularidad y gestión pública de la red telegráfica, inspiradas fundamentalmente en la experiencia francesa, quedaban fuera de cuestión. La doctrina estaba muy clara, pero esos mismos argumentos no se aplicaron al ferrocarril, también inspirado en el modelo francés. Hay que pensar, pues, que los bajos costes decidieron en último término el carácter público de la telegrafía española. El Gobierno optó por adjudicar la construcción y el material de las líneas en subastas públicas, que fueron acogidas con escaso entusiasmo por los constructores, sin duda porque los tipos eran muy bajos ${ }^{49}$.

La urgencia con que el Estado pretendía construir la red de telegrafía eléctrica chocaba con una notable insuficiencia de capitales y con la estrechez de los mercados financieros ${ }^{50}$. Era, pues, lógico que los inversores se mostraran extremadamente selectivos a la hora de comprometer su dinero. Ahora bien, la financiación recaía por entero sobre el contratista de la línea, que debía cubrir una fianza del 5 por 100 del coste y tardaba hasta un año en cobrar del Estado. Las expectativas de beneficio de los contratistas del telégrafo eran inciertas y poco elevadas. En cambio, la construcción del ferrocarril ofrecía un negocio seguro, razón poderosa que explica el entusiasmo mostrado por los inversores en este ramo ${ }^{51}$. También la especulación con suelo urbano en algunas ciudades era un negocio de elevada rentabilidad ${ }^{52}$. Adelantar dinero en las obras del telégrafo suponía detraerlo de esas inversiones más remunerativas y pagar elevados costes de oportunidad. Los que optaron por embarcarse en la construcción del

${ }^{48}$ El telégrafo público aparecía también como un medio de atajar los abusos provocados por una utilización especulativa. Según el citado E. Figueras, especuladores en Bolsa mantenían una posta hasta Francia, con un coste de 60.000 reales mensuales, que les permitía conocer las cotizaciones y otras noticias ocho horas antes que el gobierno: $D S C, 21$ de abril de 1855 , p. 4006.

${ }^{49}$ El Gobierno fijaba las cantidades máximas que se comprometía a pagar por la construcción (2.602 reales $\mathrm{km}$ por la construcción completa y 1.310 por la parcial) y los plazos de entrega de las obras. Las cantidades finales podían reducirse porque la adjudicación se hacía al mejor postor: Gaceta de Madrid, 15 de noviembre de 1855.

50 Comín y otros (1998), vol. 1, p. 62.

"La fianza se pagaba en metálico o en acciones de carreteras y ferrocarriles; la rentabilidad era aproximadamente de un 3 por 100 . Resumen de la polémica existente sobre el negocio ferroviario: Comín y otros (1998), vol. 1, pp. 142 ss.

${ }_{52}$ Tortella (1973), p. 15; Sudrià y Pascual (1999), pp. 127-145. Hubo drenaje de ahorros hacia las construcciones urbanas en Madrid y Barcelona: Bahamonde y Toro (1978), p. 31, y Tafunell (1993), p. 45. 
telégrafo trataron de obtener beneficios buscando complementariedades con el ferrocarril ${ }^{53}$ y aumentando la escala de las operaciones. Tras diversos cambios de manos de concesiones, seis contratistas se repartieron la totalidad de las obras del telégrafo subastadas en 1855. Algunos concentraron sus opciones en una sola zona, mientras otros tendieron a diversificar más su intervención.

La red telegráfica de España se plasmó en una estructura radial centralizada en Madrid, calcada, como la ferroviaria, de la red caminera existente. En actuaciones sucesivas, el Gobierno organizó el servicio creando el nuevo Real Cuerpo y Servicio de Telégrafos de 1856. El Estado dio pasos importantes hacia la universalización del servicio sin tener que recurrir a una extensión de las infraestructuras. Una fórmula consistió en poner a disposición del público el servicio telegráfico de las estaciones ferroviarias. $\mathrm{La}$ otra supuso fusionar Correos y Telégrafos en $1869^{54}$, con una clara tendencia racionalizadora: a las economías por reducción de personal y cierre de locales alquilados como estafetas se unían las economías por sinergia ${ }^{55}$. Correos aportaba personal adiestrado en el servicio de mensajería para la entrega de telegramas y un medio de ampliar el servicio a poblaciones próximas a las líneas telegráficas sin oficina de telégrafos ${ }^{56}$.

Pero la ampliación y reforma de la red resultó ineludible y así se reconoció y se llevó a cabo en 1873 , como se ha explicado. No tardaría en darse la primera y tímida entrada en el país de una nueva forma de telecomunicación eléctrica -el teléfono-y las primeras disposiciones gubernamentales que regulaban su instalación y explotación ${ }^{57}$. Una vez que el Gobierno arrebató a los Ayuntamientos la potestad de conceder y regular el sistema telefónico, éstos entrevieron la posibilidad de contar con servicio propio por medio del telégrafo. A partir de 1884, el Gobierno autorizó

${ }^{33}$ Los socios de Brusi, Lluch y Cía., contratista de la línea telegráfica Barcelona-Zaragoza, estaban vinculados a la Compañía del Ferrocarril Barcelona-Zaragoza (pese a no estar registrada, damos por sentado que los socios son M. Lluch y A. Brusi i Ferrer): AHPNB, J. Falp, 9 de abril de 1856; 18 de setiembre de 1857, fols. 461 ss., y 11 de julio de 1857 , fol. 375 .

54 Durante el ministerio de P. M. Sagasta: Gaceta de Madrid, 25 de marzo de 1869, pp. 2204 ss.

"5n Europa se buscaron generalmente esas economías por sinergia: Foreman-Peck (1989), pp. 383 ss. En Gran Bretaña, Correos absorbió a Telégrafos en 1868; dos años más tarde Italia creó los PTT; en Alemania, el personal técnico de Telégrafos se opuso a la fusión: Noam (1992), pp. 14, 18 y 240. El caso holandés ha sido estudiado por Davids (1995), pp. 194-205.

${ }^{56}$ DSC, 22 de mayo de 1869, p. 2210.

${ }^{57}$ Calvo (1998), pp. 52-81. 
a los Ayuntamientos la apertura de oficinas telegráficas a cargo del presupuesto municipal ${ }^{58}$. La medida tuvo efectos limitados (en 1895 existían 67 sobre un total de 1.421) porque los municipios prefirieron seguir la vía tradicional de la financiación estatal. Al final de la década de los ochenta se construyeron algunas líneas recurriendo al mecanismo caciquil. Podría, así, hablarse de telégrafos parlamentarios, lo mismo que se ha denominado «carreteras parlamentarias» a las conseguidas gracias a las influencias y peso que tuviera en las Cortes el distrito por el que atravesaran ${ }^{59}$. En el fondo, esta vía contradecía el principio de servicio universal que había presidido la creación de la red de telégrafos y alimentaba los agravios comparativos: pueblos pequeños tenían telégrafo mientras ciudades carecían de él ${ }^{60}$. Finalmente, este procedimiento de ampliación de la red, irregular por cuanto implicaba una intromisión de las Cortes en la esfera administrativa, se abandonó y, en 1889, el Gobierno autorizó la apertura del servicio en las cabezas de partido y en otras poblaciones de cierta importancia.

El carácter público de la red de telegrafía eléctrica española plantea el tema de sus relaciones con el sector privado, ya que las compañias ferroviarias y algunos particulares construyeron sus propias líneas. Las primeras, impuestas por la normativa gubernamental, se desarrollaron a medida que fue ampliándose la red ferroviaria a la que servían. El Estado se cuidó bien de impedir que el sector privado, minoritario aunque importante (un tercio de las estaciones y de las líneas aproximadamente), fuera un coto cerrado. Ya en 1852 se aseguró la posibilidad de utilizar las líneas telegráficas de los ferrocarriles y las particulares con fines oficiales. Aprovechando la ampliación de la legislación ferroviaria, el Estado se otorgó el derecho a utilizar en el futuro la infraestructura de las líneas telegráficas de las compañias ferroviarias para desarrollar la red telegráfica pública. Pero su búsqueda de complementariedades chocó con el desinterés o la desidia de las compañías del ferrocarril; en ocasiones, no sólo fue imposible utilizar la infraestrucura de las compañías, sino que las líneas telegráficas del ferrocarril hubieron de ser costeadas con fondos públicos ${ }^{61}$. Un paso trascendental en la política estatal fue la interconexión de los dos sistemas en 1881, así como la apertura de las estaciones telegráficas de las compañías

${ }^{58}$ DSC, 18 de junio de 1884, pp. 626-628.

${ }^{59}$ Los DSC de 1887 recogen diversos casos. Debo el comentario sobre las carreteras parlamentarias a A. Herranz.

(8) DSC, 16 de febrero de 1888 , p. 1200.

6) Olivé Roig (1993), en Bahamonde Magro y otros (eds.), pp. 141-149. 
al público ${ }^{62}$. Las trayectorias de las líneas telegráficas privadas se bifurcaron: a diferencia de las particulares, las pertenecientes a las compañías ferroviarias se mantuvieron.

Pese a los avances, una evaluación global sobre el período que finaliza con el siglo XIX no deja muy bien parado el sistema telegráfico español ${ }^{63}$. El establecimiento de un plan global y el monopolio estatal habían evitado duplicaciones de líneas inútiles y costosas. Pero la supeditación del telégrafo a las necesidades administrativas y al orden público, materializadas estas últimas en la dependencia del Ministerio de Gobernación, no era la mejor vía para impulsar una red pública que atendiera con solvencia las variadas exigencias del país. Primero, porque el objetivo primordial no era ése y, además, porque la dotación presupuestaria del Ministerio de Gobernación pesaba muy poco en los gastos totales de un Estado permanentemente endeudado. La propia fórmula de financiar el servicio telegráfico a través de los presupuestos generales del Estado y no a través de la recaudación restaba estímulos a los funcionarios responsables. De muy poco sirvieron las voces de alerta que, procedentes de la opinión pública, pretendían convertir el telégrafo en un instrumento de crecimiento ${ }^{64}$.

Por otra parte, si, en sus líneas básicas, el trazado de la red telegráfica obedecía a un plan de conjunto, la adjudicación se llevó a cabo fragmentando las líneas, por lo que la construcción recayó sobre contratistas distintos, que no necesariamente utilizaron los mismos sistemas. La irresponsabilidad de algunos de los constructores acarreó retrasos y costes adicionales en ciertas líneas. Todo ello plantea el problema de la eficacia del aparato administrativo encargado de la supervisión de las obras. Una lectura atenta de las Memorias de los inspectores de distrito sugiere la desproporción entre las enormes posibilidades de fraude en las calidades

${ }^{62}$ El Estado se reservaba la facultad de colgar líneas públicas en los postes del telégrafo del ferrocarril: Boletin Oficial del Ministerio de Fomento (BOMF), 6 de marzo de 1856, p. 417. La compañía férrea determinaba la cantidad de aparatos fijos o portátiles que debían instalarse. Para el caso de la Cía. Barcelona-Zaragoza, véase AHPN de Barcelona, J. Falp, 22 de octubre de 1856, fol. 397 , y 29 de julio de 1858 , fol. 70 .

${ }_{63}$ Personas con una viculación estrecha con el telégrafo, como Suárez Saavedra, subrayaban sus defectos y su inferioridad técnica respecto a otros países: Industria e Invenciones, 24 de diciembre de 1887, p. 307 , y 19 de enero de 1895, p. 17. Observadores extranjeros mostraban su estupor ante el estado de la telegrafía española: The Electrician, 10 de febrero de 1897 , p. 539.

ot Durante casi dos años, la construcción dependió de Fomento; en 1857 volvió a Gobernación, cuyos gastos presupuestarios suponían el 3,5 por 100 del total en el período 1850-1890: Tortella (1994), p. 160. La obsesión por el orden público ha llamado poderosamente la atención de analistas extranjeros: Nye (1997), p. 1069. 
y dimensiones de los materiales, por ejemplo, y los limitados medios para impedirlo. De hecho, la situación catastrófica del primer sistema, públicamente reconocida, indica que el control sobre el cumplimiento de las cláusulas de las contratas fue inadecuado. Tampoco el servicio se libró de las críticas por las deficiencias, retrasos y dilaciones. iCómo justificar que a veces una carta fuera más rápida que un telegrama; que fuera necesario pasar por Madrid para comunicar ciudades enlazadas por líneas directas ${ }^{65}$, o el uso discriminatorio del servicio por el Gobierno! ${ }^{66}$ En 1872, coincidiendo con un momento álgido en las críticas, algunas llegaron a cuestionar incluso el carácter público del servicio y no solamente vicios particulares.

\section{LA DEPENDENCIA TECNOLÓGICA DE LA TELEGRAFÍA EN ESPAÑA}

La experiencia de otros países ahorró a España los inconvenientes de ensayos desafortunados. El Estado pretendía adoptar la tecnología más adecuada, pero ésta se modificaba con el paso del tiempo. La construcción gradual de la red hizo variar los sistemas adoptados, mientras la necesidad de sujetarse a la normativa internacional obligó a homogeneizar la tecnología. El predominio del sistema Morse era, en los años finales del siglo $\mathrm{xIX}$, aplastante, frente al corto número de los dúplex y de los traductores ${ }^{67}$. Esto quiere decir que primó un tipo de tecnología encaminada a la explotación extensiva y que la tecnología española, aun con interesantes aportaciones, fue poco relevante ${ }^{68}$.

Teóricamente, el Estado español tuvo temporalmente en sus manos la posibilidad, si no de crear un sector eléctrico público, sí, al menos, de reforzar la base industrial autóctona en el proceso de adopción de las nuevas tecnologías de la electricidad. Así sucedió en diversos países europeos, mientras en otras latitudes incluso se fue más lejos. Para limi-

${ }^{65}$ Esta situación se daba en la línea Bilbao-Barcelona: DSC, 27 de julio de 1896, p. 1735.

${ }^{6}$ En repetidas ocasiones se llegó a acusar al Gobierno de discriminación en el envio de telegramas y obstruccionismo (revisión y retención de los telegramas que la oposición dirigía a la prensa). Los despachos oficiales, que no respetaban el orden de entrada, podían llegar a su destino por vía indirecta porque el Gobierno tenía a su disposición toda la red de la Península, mientras los particulares estaban mal atendidos: DSC, 25 de octubre de 1872 , p. 825.

${ }^{67}$ Proyecto de Ley, DSC, 15 de enero de 1855; Journal Télégraphique, 1899, p. 156.

${ }^{6}$ DSC, 8 de mayo de 1888, p. 3186; Ronquillo (1855), p. 497; Ribot (1886), p. 479. 
tarnos a dos casos, Francia supo encontrar en el telégrafo una ocasión de investigación y desarrollo, a la vez que un arranque para la ingeniería eléctrica ${ }^{69}$. En Japón, entonces todavía muy lejos de su actual liderazgo, la fabricación de equipo eléctrico autóctono arrancó de la Dirección de Telégrafos ${ }^{70}$.

En España, las cosas fueron por otro camino. Como titular del sistema telegráfico, el Estado marcaba las grandes directrices relativas a la calidad, dimensiones o tratamiento de los postes; cantidad, calidad y características de los hilos y de los aisladores, pero la elección de los modelos concretos recaía sobre los constructores ${ }^{71}$. Por otra parte, en las concesiones de cables submarinos, el Estado daba libertad a los concesionarios para escoger y cambiar la tecnología a su gusto. Las prisas por crear el sistema telegráfico anularon casi por completo los efectos hacia atrás sobre la industria nacional y se desperdició ${ }^{72}$ la ocasión de impulsar una industria autóctona de material telegráfico, que hubiera podido ser la base de un sector eléctrico de peso. Generalmente, el equipo utilizado era construido en el extranjero en régimen de monopolio. Falló también lo que podía haber sido el elemento técnico dinamizador: las expectativas generadas en 1866 por la imposición de un porcentaje elevado de ingenieros industriales al Cuerpo de Telégrafos se vieron frustradas al ser abolida la disposición. Los escasos especialistas integrados en la administración a finales del siglo XIX se mantenían por razones extrañas a su titulación ${ }^{73}$. La Escuela de Telégrafos llegó demasiado tarde: cuando se creó, en 1913, el mercado mundial de aparatos eléctricos, bajo el dominio de multinacionales, dejaba muy pocos resquicios a los nuevos aspirantes. En el tendido del sistema nacional de cables, la empresa constructora utilizó sus propios recursos humanos y materiales.

En definitiva, hay que insistir una vez más en la necesidad de incorporar los estudios sobre el telégrafo a la Historia Económica de nuestro país. Antes de conseguir llevarlos a la altura que ha alcanzado la investigación histórica sobre los ferrocarriles, por ejemplo, es legítimo pasar por una fase en la que los aspectos descriptivos de la creación y desarrollo de la red queden claramente establecidos. Es lo que ha pretendido llevar a cabo

${ }^{69}$ Sánchez Ron (1992), p. 51.

${ }^{70}$ Uchida (1991), p. 22.

7 Gaceta de Madrid, 15 de noviembre de 1855

72 Nadal (1975); Comín y otros (1998), p. 325.

${ }^{73}$ El Decreto de 1866 establecía que un tercio de los miembros del Cuerpo de Telégrafos debían ser ingenieros industriales: Garrabou (1982), pp. 99 y 102. 
este artículo, que sitúa el caso español en una perspectiva europea, insistiendo en las fases por las que atravesó la legislación y la construcción del telégrafo. Por encima de otras consideraciones, hay que subrayar que la red telegráfica española fue objeto de una planificación de conjunto, aunque no con carácter totalizador. En España, el telégrafo eléctrico tuvo un inicio tardío y un lento despegue. A diferencia de lo sucedido con las otras dos grandes redes de comunicaciones en el siglo XIX, es decir, el ferrocarril y el teléfono, el telégrafo fue construido y explotado por cuenta del Estado. Pero a la ruptura tecnológica que el telégrafo eléctrico suponía no le acompañó una ruptura en los planteamientos gubernamentales sobre la finalidad que el citado medio de comunicación debía perseguir. El gobierno español se situó a remolque de los sectores más dinámicos del país. Falta de medios, subordinación a intereses propiamente administrativos y desvinculación de los objetivos de mercado hicieron que España fuera a la zaga de otros países europeos en el desarrollo del servicio telegráfico.

\section{ARCHIVOS Y BIBLIOTECAS CONSULTADOS}

Archivo Histórico Nacional, Madrid.

Archivo Histórico de Protocolos Notariales, Barcelona.

Archivo Pirelli, Milán.

Biblioteca Nacional, Madrid.

Bibliothèque Nationale Suisse, Berna.

British Library of Political and Economic Science, Londres.

British Telecom Archives, Londres.

Fondo Antiguo de la Escuela de Ingenieros Industriales, Barcelona.

Science, Industry and Business Library, Nueva York.

\section{BIBLIOGRAFÍA}

Academia de Ciencias de Madrid (1856): Informe sobre telegrafía eléctrica, Madrid, Aguado.

Adams, Cl., y Butler, O. R. (1999): Manufacturing the Future. A History of Western Electric, Cambridge, Cambridge University Press.

ARCARONS RUA, M. (1993): «Empresa privada y condicionantes políticos en las comunicaciones telegráficas intercontinentales españolas, 1855-1895», en Bahamonde Magro, A., y otros (eds.), pp. 151-164.

Bahamonde Magro, Á. (dir.) (1993): Las comunicaciones en la construcción del Estado contemporáneo en España, 1700-1936, Madrid, MOTMA. 
Bahamonde Magro, Á., y otros (eds.): Las comunicaciones entre Europa y América, 1500-1993, Madrid, I Congreso Internacional sobre Comunicaciones.

Bahamonde Magro, Á.; Martínez Lorente, G., y Otero Cavajal, L. E. (1998): Atlas bistórico de las comunicaciones en España, Madrid, Correos y Telégrafos.

Bahamonde, Á., y Toro, J. (1978): Burguesia, especulación y cuestión social en el Madrid del siglo XIX, Madrid, Siglo XXI.

BEZzA, B. (1987): «L'attività multinazionale della Pirelli (1883-1914)», Società e Storia, núm. 35, 1987, p. 59.

BRÉGUET, L. (1851): Manuel de la Télégraphie Électrique, Paris.

Calvo, A. (1993): «Orígenes de las nuevas tecnologías de la comunicación en Cataluña: la telegrafía», II Trobades d'Historia de la Ciència $i$ de la Tècnica, Barcelona, SCHCT, pp. 189-205.

- (1998): «El teléfono en España antes de Telefónica», Revista de Historia Industrial, núm. 13 , pp. $52 \cdot 81$.

- (2000): «Los cables submarinos: una rama emergente de la ingeniería civil en el siglo XIX», Quaderns d'Història de l'Enginyeria, núm. 4 (en prensa).

CAPEL, H., y TATJER, M. (1994a): «La organización de la red telegráfica española», en CAPEL, H., et al. (coord.), Ciencia e ideologia en la ciudad, I Coloquio Interdepartamental, vol. II, Generalitat Valenciana, pp. 23-69.

- (1994b): «El telégrafo en Barcelona», en VAA, Espacio, tiempo y arte. Homenaje al profesor $A$. Bonet Correa, Madrid, Universidad Complutense, pp. 1065-1102.

CARON, F. (1997): Les deux révolutions industrielles du xxe siècle, Paris, A. Michel.

CARLSSON, C. M. (1999): «New Information Technologies. The Telegraph in Sweden 1853-1883», Summer School of the European Historical Economics Society in Lund, Sweden, inédito.

CARRÉ, P. A. (1992): «Du télégraphe au télex», History and Technology, núm. 8 pp. 275-283.

Casson, M. (1994): «The Economics of Information and the Historical Evolution of Firms and Markets», XI International Economic History Congress, Milán, ejemplar mecanografiado (cortesía de F. Antolín).

CoE, L. (1993): The Telegraph: A History of Morse's Invention and its Predecessors in the United States, Jefferson, McFarland.

Comín, F. (1996): Historia de la Hacienda pública, I, España, Barcelona, Crítica. - (1998): 150 Años de Historia de los Ferrocarriles Españoles, Madrid, Anaya.

Chappe, M. (1824): Histoire de la télégraphie, Paris.

Chenut, L. (1884): «Note sur le télégraphe Estienne», L'Électricien, 15 de abril, pp. 396-397, y (1885) 7 de marzo, pp. 187-188.

DAvid, P. A. (1991): «The Hero and The Herd in Technological History», en Higonnet, P. et al. (ed.) (1991), p. 77.

DAVIDS, M. (1995): «The Relationship between the State Enterprise for Postal, Telegraph and Telephone Services and the State in the Netherlands in Historical Perspective», Business and Economic History, 24, 1, primavera, pp. 194-205.

Del Grande, E. (1994): «I cavi telegrafici sottomarini. Contributo alla storia delle industrie Pirelli (Ricordi di un vecchio cavista)», ejemplar mecanografiado, Archivo Pirelli (Milán), 1944. 
Depelley, J. (1900): «Les cables télégraphiques en temps de guerre«, Revue des Deux Mondes, 1 de enero, p. 200.

Dictionnaire technologique ou Nouveau dictionnaire Universel des Arts et Métiers (1832), XX, Paris.

Du Boff, R. B. (1983): «The Telegraph and the Structure of Markets in the United States, 1845-1890», Research in Economic History, núm. 8, pp. 253-277.

ELI, N. (1992): Telecommunications in Europe, New York y Oxford, Oxford U. P.

EstabrooKs, M. (1995): Electronic technology, corporate strategy, and world transformation, Westport and Londres, Quorum.

FARR, W. (1876): «On the Valuation of Railways, Telegraphs, Water Companies and Canals», Joumal of The Statistical Society, septiembre, p. 484.

FIELD, A. (1999): «The Telegraphic Transmission of Financial Asset Prices», $A b s$ tracts AEH, The Journal of Economic History, 59, 2, junio, p. 496.

FIELD, A. J. (1994): «French Optical Telegraphy, 1793-1855: Hardware, Software, Administration», Tecbnology and Culture, abril, pp. 315-347.

Flichy, P. (1993): «Genèse des réseaux de télécommunication dans l'Europe de la première moitié du $19^{e}$ siècle», en Bahamonde MAGRO, Á., y otros (eds.), Las comunicaciones entre Europa y América, 1500-1993, Madrid, I Congreso Internacional sobre Comunicaciones.

Foreman-Peck, J. (1989): «L'État et le dévéloppement du réseau de télécommunications en Europe à ses débuts», Histoire, Économie et Société, núm. 3, pp. 383-399.

Foreman-Peck, J., y Múller, J. (eds.) (1988): European Telecommunication Organisations, Baden-Baden, Nomos.

Garrán, M. (1856): «Telégrafos eléctricos», Revista de Obras Públicas, núms. 10, pp. 109-110, 126-129, 151-155; 14, pp. 157-160; 15, pp. 169-171; 16, pp. 181-182; 18, pp. 205-207, y 21, pp. 241-245.

GARRABOU, R. (1992): Enginyers industrials, modernització econòmica i burgesia a Catalunya, Barcelona, L'Avenç.

Garrido, F. (1865): La España contemporánea, Barcelona, S. Manro.

Gavarret, J. (1861): Télégraphie électrique, Paris, V. Masson et Fils.

Gemmell, N., y Bardley, P. (1990): «The Contribution of Services to British Economic Growth, 1856-1913», Explorations in Economic History, núm. 27, pp. 299-321.

Gérard, A. (1889): «Le poste central des Télégraphes à Saint Petersbourg», Revue Internationale de l'Electricité et de ses Applications, núm. 84, 20 de junio, pp. 444-446.

Gómez Mendoza, A., en Carreras, A. (1989): Estadísticas bistóricas de España, ss. $X I X-X X$, Madrid, Fundación Banco Exterior.

Gómez Mendoza, A., en Comín, F., y Martín Aceña, P. (dir.) (1991): Historia de la empresa pública en España, Madrid, Espasa-Calpe, pp. 177-204.

GONZÁlez y MOLADA, J. (1875): «Telégrafos militares. Breve reseña história de este medio de comunicación», inédito, Archivo de la Corona de Aragón.

GrISET, P. (1987): «L'État et les télécommunications internationales au début du xxe siècle en France: un monopole stérile», Histoire, Économie et Société, núm. 2, pp. 181-207. 
- (1991): Les révolutions de la communication, Paris, Hachette.

HeADRICK, D. R. (1990): The Invisible Weapon: Telecommunications and International Politics, 1851-1945, New York.

Hobsвawm, E. J. (1977): La era del capitalismo, 1, Madrid, Guadarrama.

Holcombe, A. N. (1911): Public Ownership of Telephones on the Continent of Europe, Boston y New York, The Riverside Press.

HuBbaRD, F. (1968): Cooke and Wheatstone and the invention of the electric telegraph, Nueva York, A. M. Kelley.

Hunt, B. J. (1991): «Michael Faraday, Cable Telegraphy and the Rise of Field Theory», en Hollister-Short, G., y James, F. J. L. (eds.), History of Tecbnology, 13, Mansel.

IGLESIES, J. (1965): La contribució catalana al telègraf elèctric, Barcelona, R. Dalmau. IsRaEl, P. (1992): From Machine Shop to Industrial Laboratory: Telegraphy and the Changing Context of American Invention, 1830-1920, Baltimore-London, Johns Hopkins U. P.

IsRael, P. B., y NeIR, K. (1991): «The Transfer of Telegraph Technologies in the Nineteenth Century», en JEREMY, D. J. (ed.) International Technology Transfer, Europe, Japan, and USA, 1700-1914, Eldershot, E. Elgar.

JONA, E. (1896): Cavi telegrafici sottomarini.Costruzzione, immersione, riparazione, Milano, Archivo Pirelli, pp. 38-39.

KENWOOD, A. G., y LOOUGHEED (1982): Technological Diffusion and Industrialization before 1914, New York, St. Martin's Press.

KIEve, J. (1973): The electric Telegraph. A social and economic bistory, London.

KranTZ, O. (2000): «The Transport and Telecommunication Sector in Economic Development: Views from the Historical National Accounts», Scandinavian Economic History, núm. 48, pp. 5-29.

KAUKIAINEN, Y. (2001): «Shrinking the world: Improvements in the speed of information transmission, c. 1820-1870», European Review of Economic History, núm. 5, pp. 1-28.

LAMOREAUX, N., y SOKOLOFF, K. L. (1999): «Inventive activity and the market for technology in the United States, 1840-1920», NBER Working Papers Series, mayo.

LEE, J. (1913): The Economics of Telegraph and Telephone, London.

Malone, L. J. (2000): «Telegraphs to Incandescent Lamps: a sequential process of Innovation», Essays on Economics and Business History, XVIII, pp. 123-134.

MAluquer de MOTES, J. (1977): El socialismo en España, 1833-1868, Barcelona, Crítica.

MARTWELL, R. M. (1979): «La revolución de los servicios: el crecimiento del sector servicios en la economía moderna», en Cipolla, C. M. (ed.), Historia económica de Europa, vol. 3. La revolución industrial, Barcelona, Ariel, p. 389.

Mokyr, J. (1990): «Punctuated Equilibria and Technological Progress», The American Economic Review, 80, 2, mayo, p. 353.

NADAL, J. (1975): La revolución industrial en España, 1814-1913, Barcelona, Ariel

Nier, K., y Butrica, A. J. (1998): «Telegraphy Becomes a World System», en Essays in Economics and Business History, núm. 6, pp. 211-226.

NONNENMACHER, T. (1997): «Law, emerging technology and market structure», Journal of Economic History, núm. 57, junio, pp. 488-490. 
NYE, D. E. (1997): «Shaping Communication Networks: Telegraph, Telephone, Computer», Social Research, 64, 3, pp. 1067-1091.

O'MEARA, M. (1913): Report on the Telegraph and Telephone Services of Belgium, British Telecom Archives, London, BTA.

- Report on the Telegraph and Telephone Services in Italy, London, BTA.

Olví RoIG, S. (1993): «Influencia del ferrocarril en el nacimiento del telégrafo en España», en BaHAamonde MaGro, Á., y otros (eds.), pp. 141-149.

Otero Carvajal, L. E. (1993): «El Estado y la red telegráfica en España, 1852-1936», en BAHAMONDE MAGRO, Á., y otros (eds.), pp. 121-127.

PERRY, C. R. (1997): «The Rise and Fall of Government Telegraphy in Britain», Business and Economic History, 26, 2, pp. 416-425.

Preece, W. H. (1894): «Notes of a Trip to the United States and to Chicago, 1893», The Electrician, 2 de febrero, pp. 354-357.

Prescott, G. B. (1860): History, Theory, and Practice of the Electric Telegraph, Boston, Ticknor and Fields.

- (1877): Electricity and the Electric Telegraph, New York, Appleton.

Ribot, J. (1886): «Un progreso en telegrafía», El Porvenir de la Industria, 3 de diciembre, pp. 479-480.

Rodriguez Maroto, E. (1943): iLaureles viejos! Un breve bistorial de telégrafos en el siglo XIX, Madrid, Gráficas O. Alonso.

RÖlleR, L.-H., y WAVERMAN, L. (2001): «Telecommunications infrastructure and Economic Development: A Similtaneous Approach», The American Economic Review, 91, 4, septiembre, pp. 909-923.

Ronquillo, J. O. (1855): Diccionario de materia mercantil, industrial y agricola, que contiene la indicación, la descripción y los usos de todas las mercancías, Barcelona, I. de A. Gaspar.

Samuel, P. (1886): «Considérations sur le système télégraphique imprimeur de M. J. Munier», Revue Internationale de l'Électricité et de ses Applications, 20 de agosto, p. 144.

SÁnCHEZ-AlborNOz, N. (1975): «La progresión de la comunicación postal», en Jalones de la modemización de España, Ariel, Barcelona, pp. 85-97.

Sánchez Ron, J. M. (1992): El poder de la ciencia, Madrid, Alianza.

SOBEL, R. (1993): The Age of Giant Corporations, Westport and London, Greenwood Press.

StANDAGE, T. (1999): The Victorian Internet: the remakable story of the telegraph and the nineteenth century's on-line pioneers, New York, Berkeley Books.

SuÁrez SaAvedra, A. (1880): Tratado de telegrafía, Barcelona, J. Jepús.

SUDRIA, C., y PASCUAL, P. (1999): «Financing a railway mania: capital formation and the demand for money in Catalonia, 1840-66», Financial History Review, núm. 6 , pp. 127-145.

TAfunell, X. (1994): La construcció de la Barcelona moderna, Barcelona, Ayuntamiento de Barcelona.

Thomson, R. L. (1947): Wiring a Continent: The History of the Telegraph Industry in the United States, 1832-1866, Princeton, New Jersey.

TORTELlA, G. (1973): Los orígenes del capitalismo en España, Madrid, Taurus.

- (1994): El desarrollo de la España contemporánea. Historia económica de los siglos XIX y XX, Madrid, Alianza. 
Toussaint, M. (1881): «La télégraphie en France», Revue Scientifique, núm. 10 de septiembre, pp. 471-474.

UCHIDA, H. (1991): «The Transfer of Electrical Technology from the United States and Europe to Japan, 1869-1914», en JeREMY, D. J., pp. 219-242.

VAIL, A. (1845): The American Electromagnetic Telegraph, Filadelfia, Lea \& Blanchard.

Wilson, G. (1976): The Old Telegraphs, London, Phillimore. 